\title{
Upper Elementary and Middle Grade Teachers' Perceptions, Concerns, and Goals for Integrating CS into Classrooms
}

\author{
Mehmet Celepkolu Erin O’Halloran Kristy Elizabeth Boyer \\ University of Florida \\ Gainesville, FL, USA 32611 \\ mckolu@ufl.edu, erinohall@ufl.edu, keboyer@ufl.edu
}

\begin{abstract}
As efforts to integrate computer science into K-8 teaching in the US are dramatically rising, professional development workshops for teachers are becoming widespread. An open challenge for the CS education community is to understand teachers' needs and develop empirically grounded best practices for professional development. This experience report describes a five-day professional development workshop in which 22 third through eighth grade teachers learned about fundamental CS concepts, practiced coding, and created lesson plans for integrating what they learned into their classroom. We describe the professional development workshop including its modules and sequencing, and present teachers' perception of CS and how to integrate it into their classrooms. Teachers achieved significant gains in technical knowledge and improvements in attitude toward computer science. In initial focus groups, teachers reported that limited exposure to CS, time constraints, and lack of understanding of CS are barriers to integrating it into their classrooms. After the workshop, focus group feedback indicated that the workshop provided teachers a clearer sense of the potential of CS to enhance their classroom plans. Teachers noted that they felt able to use CS to help students learn critical thinking, prepare them for their futures, and address their individual needs. The results of this experience can inform future workshops that address the needs of teachers and students.
\end{abstract}

\section{CCS CONCEPTS}

- Social and professional topics - computing education

\section{KEYWORDS}

Teacher Professional Development; K-8 Education Training; Teacher Perception of CS

Permission to make digital or hard copies of all or part of this work for personal or classroom use is granted without fee provided that copies are not made or distributed for profit or commercial advantage and that copies bear this notice and the full citation on the first page. Copyrights for components of this work owned by others than ACM must be honored. Abstracting with credit is permitted. To copy otherwise, or republish, to post on servers or to redistribute to lists, requires prior specific permission and/or a fee. Request permissions from permissions@acm.org.

SIGCSE '20, March 11-14, 2020, Portland, OR, USA.

(C) 2020 Association for Computing Machinery.

ACM ISBN 978-1-4503-6793-6/20/03...\$15.00.

https://doi.org/10.1145/3328778.3366937

\section{ACM Reference format:}

Mehmet Celepkolu, Erin O'Halloran and Kristy Elizabeth Boyer. 2020. Upper Elementary and Middle Grade Teachers' Perceptions, Concerns, and Goals for Integrating CS into Classrooms. In Proceedings of the 51st ACM Technical Symposium on Computer Science Education (SIGCSE '20), March 11-14, 2020, Portland, OR, USA. ACM, New York, NY, USA, 7 pages. https://doi.org/10.1145/3328778.3366937

\section{Introduction}

Exposing students to computer science at the K-8 level is an increasingly important area of emphasis in policy and practice $[17,21]$. Teachers play a key role in this process, and equipping them to foster computer science learning is a crucial challenge as many teachers struggle to find computer science (CS) learning opportunities and sometimes feel isolated from other teachers $[12,19]$. The CS education community is increasingly filling this gap with professional development workshops for teachers $[5,8]$. Teachers who participate in these professional development experiences can then foster student achievement [20] and affect the transformation of students' beliefs and experiences [15].

Although many professional development experiences are being developed and deployed at present, it is becoming increasingly clear that tailoring professional development experiences based on teacher goals and expectations is important $[6,10,13]$. An open question for the CS education community is to understand the perceptions, concerns and goals that teachers bring to professional development workshops and how to develop empirically grounded best practices to address their needs. In this experience report, we describe a five-day professional development workshop in which 22 third through eighth grade teachers learned about fundamental CS concepts, practiced coding, and created lesson plans for integrating what they learned into their classroom.

This experience report discusses a problem of continuing importance to the SIGCSE community and its contributions are twofold: First, we describe the professional development workshop including its modules and sequencing, along with an analysis of the lesson plans teachers chose to create during the professional development workshop. The goal of this description is to provide insight into teachers' experiences and inform future professional development efforts. Second, we present learning outcomes and shifts in teacher dispositions over that week-long experience. The goal of this investigation is to shed light on 
teachers' current beliefs and understanding of CS, the challenges that may prevent upper elementary and middle school teachers from using CS in their classrooms, and how they can be supported in recognizing the educational potential of CS.

\section{Related Work}

It has been widely recognized that professional development of teachers in CS is imperative to actual integration of CS in the classroom [4,16]. Prior professional development workshop studies have shown the importance of intertwining workshops with teachers' needs and goals for their classroom [4,11]. In a recent study on the Exploring Computer Science (ECS) professional development model and its impact on teachers' practice, Goode et al. [5] used activities based on DarlingHammond's research [1] that found highly effective teachers consider fostering individual and strategic thinking, adapting to student needs, and drawing connections between prior student knowledge and subject content. Teachers may be even more inclined to advance their knowledge and incorporate it into their teaching if they see direct application of CS to their subject through materials they create or are exposed to. Studies show the importance of providing guidance or instructional material on how to incorporate CS into their respective subjects $[9,12,15]$.

Previous workshops have successfully used a variety of videos, unplugged activities and small breakout sessions to teach workshop material [8,14]. In a recent summer professional workshop designed to provide more advanced CS content to CS teachers, Leyzberg et al. [8] used a combination of live lectures, lecture videos and small group assignments. Another example is the experience report on Code.org's K-5 CS Fundamentals (CSF) program in which the CSF workshop agenda facilitates learning through small groups where teachers are instructed to act as students as another teacher teaches a CS lesson [14]. The Code.org-trained facilitator then provides feedback to the teacher, and other colleagues discuss what may have helped or distracted from their learning in the mock lesson. Small groups allow for teachers to learn more actively, rather than passively sitting through lecture material or feeling as if their questions are dominated by colleagues who know more [11]. The lack of knowledge of CS concepts and confidence in the material are also substantial obstacles to classroom implementation $[9,11,14]$ and thus, previous workshop studies often use these levels of CS knowledge and confidence in material as indicators of success [14]. We build on this related work by examining outcomes as well as teachers' perceptions, concerns, and goals before and after the workshop as expressed through focus groups.

\section{Methods}

\subsection{Participants}

We recruited teachers from our local school district through email-initiated flyers from the district headquarters' science coordinator. We received 44 applicants to the workshop and accepted all who were available on the chosen dates. Therefore, this experience report focuses on the $223^{\text {rd }} 8^{\text {th }}$ grade teachers, of which there were 2 male teachers and 20 female teachers. Out of 22 teachers, there were 15 upper elementary (grade $3^{\text {rd }}-5^{\text {th }}$ ) and 7 middle school (three science and four math) teachers. Race/ethnicities were White/Caucasian (10), Black/AfricanAmerican (8), Hispanic/Latino (1) and Multiracial (1). The average teaching experience was 11 years, with the max being 28 years and the min being 1 year. On a self-report survey, 13 teachers reported that they did not have any coding experience, 7 teachers reported a little, 1 teacher reported some and 1 teacher reported a lot of coding experience.

\subsection{Workshop Structure}

The workshop consisted of a 5-day intense program which included introduction of general computer science principles, implementation of Computer Science Standards, small-group working sessions, and lesson activity presentations.

On Day 1, we first conducted focus groups and administered the pre-quiz and surveys (these instruments are described in Section 3.3). The workshop continued with an introduction to computer science, a walkthrough of "Hello World" in a syntaxheavy language, followed by "Hello World" in a block-based language. After the lunch break, teachers played the 10-level Blockly Maze Game [22], which provides a soft introduction to programming concepts. Next, they were introduced to the Snap! block-based programming.

The Day 1 Snap! Activity covered sequencing, loops, and conditionals. Next, we presented an overview of the State Computer Science Standards. Most teachers were not aware that our state had adopted CS standards for K-12. We ended Day 1 with a whole-group debrief and noted teachers' suggestions for the following day. One such suggestion was the teachers felt they were spending too much time in front of the screen, so we added a CS Unplugged activity to the schedule.

On Day 2, teachers began by creating their own maze game inspired by the one they had played on the previous day. In this activity, they created their own sprites, imported images, animated them by using concepts such as loops and conditionals. Next, they moved to an unplugged activity in which they created an algorithm by using a set of instructions to direct their classmates to reproduce a drawing.

Day 3 began with a presentation on the CS Ed projects being conducted in the facilitators' lab, so that teachers understood future partnership opportunities. Then, breakout working groups resumed. At the end of the day, working groups gave a one-minute presentation on the lesson plan they had decided to develop. This early presentation allowed teachers to be exposed to other groups' activities and give each other feedback. We also selected one working group who had completed their lesson plan to guide the whole group through it on the following morning.

Day 4 began with a middle school working group leading the other teachers through their coding activity as a mock classroom. They presented how to create a model that explains the "Cell Cycle", more specifically mitosis cell division. The activity covered several fundamental computing concepts such as loops, conditionals, expressions, variables, and object-oriented programming (Figure 1). 

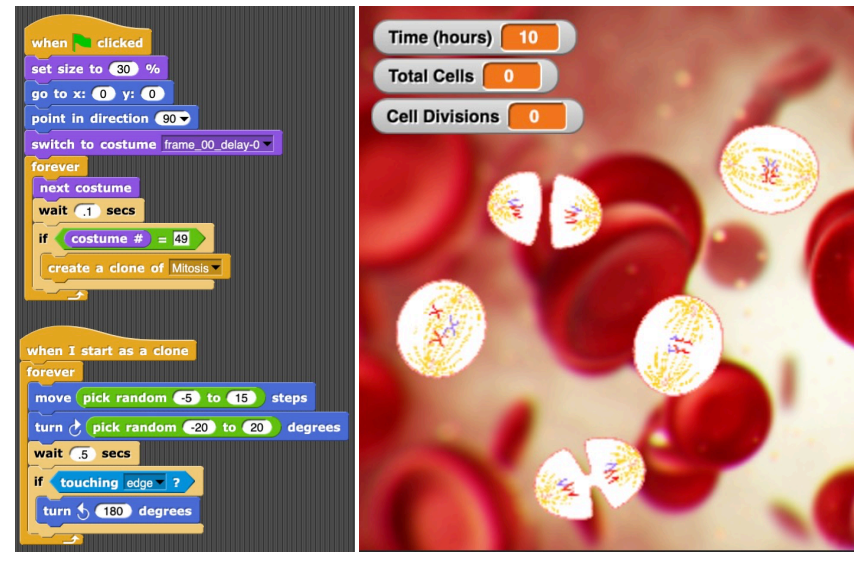

Figure 1. Sample coding activity with Cell Cycle

The group created a sample lesson plan in the format that they could utilize in a real classroom. They defined the goal for this activity as to teach students how to use counters during mitosis cell division because understanding mitosis cell division and counting the new generated cells can be challenging. Moreover, using an engaging visual via Snap! will help students to gain knowledge and see the practical use of counters in everyday life. Their lesson plan included important categories such as "desired results" and "assessment evidence."

On Day 5, two more working groups, both from elementary school, facilitated whole-class activities. The first group presented how to use a simulation for rounding a value to the nearest tens or hundreds. The second group presented a program they created on identifying and categorizing multiple quadrilaterals. After these activities, all teachers presented the final version of their lesson plan and the final activity that they created. Day 5 continued with data collection including postsurveys, the post-test, and focus groups (Section 3.3).

\subsection{Data}

Teachers completed the CS Attitude Survey prior to participating in the workshop and at its conclusion. This validated survey has five subscales [18] of which we used three: confidence, motivation and usefulness. In addition to the CS Attitudes Survey, we administered a 17-item knowledge assessment consisting of a combination of multiple-choice and short-answer items involving concepts and interpreting block-based code [3]. We had four focus groups [7] ranging from three to seven participants. We recorded audio and video of the focus group interviews and applied annotations (Section 4.3).

\section{Results}

\subsection{Quantitative Outcomes}

Teachers showed significant computer science knowledge gain over the course of the workshop. The average pretest score was 6.79 out of $17(\mathrm{SD}=3.43)$ and the average post test score was 12.26 $(\mathrm{SD}=2.42)$. This difference is statistically significant based on a paired-samples $t$-test $(t(17)=8.034, p<0.001, d=.84)$. Teachers also showed significantly more positive attitudes toward computer science after the workshop than before. The mean CS Attitude score before the workshop was 59.5 out of $85(\mathrm{SD}=13.6)$ and the mean afterward was 66.6 out of $85(\mathrm{SD}=11.4)$. This difference is statistically significant based on a paired-samples $t$-test $(t(18)=$ $2.59, p=0.02, d=0.57)$. Further analysis of each subscale of the CS Attitude Survey showed that the workshop significantly improved their confidence scores $(t(18)=3.06, p<0.01, d=0.66)$ and motivation scores $(t(18)=3.43, p<0.01, d=0.96)$. However, the difference between pre and post usefulness was insignificant $(t(18)=-1.55, p=0.14, d=0.29)$. Teachers held a very high sense of usefulness already upon entering the workshop according to the pre-survey (24.5 out of 30 ) and this value was statistically similar (23.5 out of 30 ) afterward.

\subsection{Thematic Analysis of Focus Group Data}

Thematic analysis is a qualitative methodology recommended as "a method for identifying, analyzing and reporting patterns (themes) within data" [2]. Four facilitators administered the focus groups, which consisted of between three and seven teachers from the same grade group (one middle school science, one middle school math group, and two grade 3-5 focus groups) and the same groups were interviewed before and after the workshop. The pre-focus group questions centered around teachers' previous experiences with CS; how they see the relationship of their lesson content to CS; whether they have the knowledge and skills to integrate CS into their courses; and their expectations from the workshop. On the other hand, post-focus group questions covered topics on how teachers' perception changed after the workshop; teachers future plans for CS integration in their course content; and their suggestions on how the workshop could be improved. The questions asked in the focus groups are as follows:

\section{Examples of Pre-Focus Group Questions}

- What comes to mind when you think about computer science?

- Do you think computer science can be integrated into your classroom? In what ways?

Examples of Post-Focus Group Questions

- How have your thoughts about computer science changed since the start of the workshop?

- Do you plan on integrating CS into your classroom? If so, in what ways?

- Do you have any suggestions on how the workshop could have been improved? Or vice versa, did anything specifically help you learn CS?

After the workshop, teacher focus group interviews were manually transcribed, and we followed an inductive coding ${ }^{2}$ approach to annotate the transcripts and perform thematic analysis. Two researchers annotated each focus group transcript independently and then met to discuss each one before annotating the next focus group transcript. As part of this

\footnotetext{
2 In qualitative analysis, "coding" or "annotation" refer to applying labels to data Although subjectivity is a risk in all qualitative analysis, we follow best practices of having two annotators independently work and then negotiate consensus on the most appropriate label for each data point.
} 
process, they revised the set of labels four times before finalizing them. Initially, a total of 202 independent labels were generated from the pre-focus groups and 257 independent labels from the post-focus groups interviews. For example, "feeling pressured to use technology", and "feeling nervous about coding" are some labels that emerged from analysis. Next, highly similar labels were collapsed, and a revised set of 102 labels for pre-focus group interviews and 140 post focus group interview labels were created. After this iteration process, the researchers sorted the thematically similar labels from the revised set, ultimately identifying seven themes as shown in Table 2.

Table 2. Themes from the Focus Group Interviews

\begin{tabular}{|l|l|}
\hline PRE-FOCUS & $\begin{array}{l}\text { 1: Teachers' limited exposure to CS relates to } \\
\text { misconceptions and some negative feelings. }\end{array}$ \\
\cline { 2 - 3 } INTERVIEW & $\begin{array}{l}\text { 2: Time constraints, lack of understanding of } \\
\text { CS, and differences in student preparedness } \\
\text { prevent teachers from integrating CS into } \\
\text { their courses. }\end{array}$ \\
\cline { 2 - 3 } & $\begin{array}{l}\text { 3: Teachers bring internal and external } \\
\text { motivation to learn CS. }\end{array}$ \\
\hline \multirow{4}{*}{$\begin{array}{l}\text { POST-FOCUS } \\
\text { INTERVIEW }\end{array}$} & $\begin{array}{l}\text { 4: The workshop helped teachers build } \\
\text { confidence in teaching and learning CS. }\end{array}$ \\
\cline { 2 - 3 } & $\begin{array}{l}\text { 5: The workshop gave teachers a clearer } \\
\text { insight into the educational potential of CS in } \\
\text { relation to their lesson plans. }\end{array}$ \\
\cline { 2 - 3 } & $\begin{array}{l}\text { 6: CS can help students learn problem solving, } \\
\text { critical thinking and prepare for future, } \\
\text { addressing their individual needs. }\end{array}$ \\
\cline { 2 - 3 } & $\begin{array}{l}\text { 7: The effectiveness of the workshop could be } \\
\text { improved by more individualized approaches, } \\
\text { providing additional resources and further } \\
\text { collaboration opportunities. }\end{array}$ \\
\hline
\end{tabular}

Theme 1: The focus group interviews revealed that most teachers had only had very limited exposure to CS before. These teachers reported that many of their students would have more CS knowledge than them and they usually struggle with keeping up with their students. The teachers often displayed the misconception of CS as relating to general classroom technology such as clickers, Power Point, and Google Classroom. Some teachers referred to CS as "difficult" and "frustrating".

Theme 2: Teachers reported several challenges that prevent them from integrating CS into their classrooms. When we asked whether CS can be integrated into their lessons, one teacher said:

"I feel like it's something that needs to be but I feel like I don't even know how to cross the river. I don't even know what I don't know to need to know how to implement that kind of stuff."

Similarly, another teacher answered the question by emphasizing the importance of training:
"I think yes if we're given the training and tools to do it because right now I'm just asking how do I approach it."

Some teachers reported having limited time to cover the lesson topics in the curriculum in a semester. Feeling the time pressure leads them to be more critical in using any tool that might need extra effort or time:

"I came from teaching $X$ where it is like, 'Oh I have a test coming up, I have got EFC in $X$ amount of months. When am I going to have time to go to the computer lab?' Like the pressure is there but also the constrains of I have these deadlines type deal."

Teachers also reported concerns about the extreme differences in students' readiness to learn CS. For example, only a subset of students has resources and exposure to computers at home.

"Time constraint is a big thing... Lower income students don't understand what I would refer to as some of the basics of using a computer that it would take some much longer to walk them through everything else to be able get to our final project."

Theme 3: Teachers reported high motivation to learn new skills and integrate them into their classrooms with efficient training. Teachers expressed their own internal motivations such as a desire to learn new things, for example:

"Not making it so scary for me because one of the biggest problems as a teacher is if I am afraid of using it..."

Other teachers indicated the pressure that they feel to learn CS:

"For the program I thought because it was technology, I felt like I need more real-world applications... I need skills, I need knowledge, I need more than I have..."

Theme 4: The post focus group interviews indicated a clear difference in teachers' feelings toward CS. One of the teachers described how she felt impressed with herself after achieving a programming task as follows:

"I feel more comfortable. I don't feel like programming/coding is this horrible mysterious something I am never gonna learn type of a deal. Like I think it is more accessible than what I previously thought."

Another teacher reported feeling confident:

"I definitely feel like it is approachable for me now and something that I could actually, regardless of the problem, I could eventually get to a solution whether it would be through my own trial and error or finding outside resources... Definitely much more comfortable and much more feeling like it is something that I am capable of ..."

Theme 5: In addition to helping teachers learn CS concepts, the workshop also gave them clearer insight on how to make a connection between their classroom activities and CS. 
"Abstract concepts for sure... Cells are really hard to get kids interested about because they are like 'I don't see these things unless I look under a microscope"”

Another teacher expressed the importance of utilizing coding tasks for collaborative problem-solving activities:

"I liked the fact that we saw a lot of opportunities for them to learn how to collaborate together... The idea that you can talk to your friend and you guys together can make this."

Theme 6: Some teachers emphasized how they always try to encourage students to think more critically and how coding can help achieve that goal:

"I learned how critical thinking, math and reading can be incorporated into coding because you do need all of those skills...”

Similarly, another teacher stated that coding would urge students to approach the problem-solving process differently:

"They [students] always try to quickly get to the answer so with this [coding] it will make them stop and think about each step in the process... They would enjoy it."

Teachers also noted these skills can be transferred to any work in future and coding can help them gain these skills: Thus, they have the motivation to learn CS to better prepare students for the future workforce:

"There are so many careers opening up in CS I want to be able to bring that to them in a more savvy way."

Theme 7: Teachers reported that the resources helped them learn better and provided some suggestions on how to improve the workshop.

"Small groups were amazing... You got to do one to one, you got to do some group work, you got to ask questions. You didn't feel 'Oh! This is dumb!'”

Seeing other teachers lesson plans' and learning about additional resources are also very useful to teachers.

"It was really beneficial that you all gave us to create something that we can use in our classrooms because a lot of time you go to these workshops and we are just like how does this apply to me.”

\section{Discussion and Implications}

This experience report has described a one-week workshop for $3^{\text {rd }}$ through $8^{\text {th }}$ grade teachers, including its outcomes on learning and teachers' dispositions toward computer science. Focus group and pre-test results show that teachers entered the workshop with very little computer science experience and many teachers felt intimidated by the subject matter. Post-test results show that teachers achieved significant learning gain on the computer science material covered in the workshop, and in focus groups at the conclusion of the workshop teachers reported that they had formed goals regarding how to integrate CS into their classrooms. They expressed how experiencing coding during the workshop allowed them to see its potential for teaching critical thinking and learning how to break down a process. They also saw the potential of computer science activities to improve students' perseverance and prepare them for future learning.

This experience provides several implications for future professional development workshops.

- Small group activities are very helpful for teachers to ask questions and receive immediate feedback.

- Activities should be tailored to teachers' goals and needs. Teachers have drastically different knowledge levels and goals. Workshop organizers should set aside time to adapt the plan after each day (or even during each lunch break) based on teachers' needs.

- Teachers face important challenges around time limitations. It is important that teachers leave a professional development workshop with completed lesson plans they have helped create.

- As teachers produce projects and lesson plans during the workshop, bundling the materials together as a resource provides teachers with additional materials for integrating CS into their classrooms.

\section{Conclusions and Future Work}

As we move toward broader K-12 integration of computer science, supporting teachers in developing computer science expertise is a crucial concern. Developing an empirically informed set of best practices for how to do this requires considering the perspectives, concerns, and goals of teachers so that we can best serve them. This paper has described a professional development workshop and its outcomes, which included significant computer science knowledge gain as well as increased positive attitudes in terms of confidence and motivation toward CS. Thematic analysis of focus groups indicates that CS is an intimidating area for most teachers, but they are motivated to learn new skills and integrate them into their classrooms with training. They have many internal and external motivations for doing so, and designing effective professional development workshops to help them realize this potential is a crucial goal.

Future work should investigate the ways in which teachers' learning in professional development translates into their classroom practice. Additionally, we must continue to support teachers from diverse backgrounds and subject areas. This work can support the integration of computer science throughout K-12 education.

\section{ACKNOWLEDGMENTS}

This research was supported by the National Science Foundation through grant DRL-1640141. Any opinions, findings, conclusions, or recommendations expressed in this report are those of the authors, and do not necessarily represent the official views, opinions, or policy of the National Science Foundation. 


\section{REFERENCES}

[1] B Barron and L Darling-Hammond. 2008. Teaching for Meaningful Learning A Review of Research on Inquiry-Based and Cooperative Learning. Book Excerpt. George Lucas Educational Foundation.

[2] V Braun and V Clarke. 2006. Using thematic analysis in psychology. Qualitative Research in Psychology 3(2), 77-101.

[3] HE Chipman, FJ Rodríguez, and KE Boyer. 2019. "I Impressed Myself With How Confident I Felt": Reflections on a Computer Science Assessment for K8 Teachers. In Proceedings of the 50th ACM Technical Symposium on Computer Science Education - SIGCSE '19, 1081-1087. https://doi.org/10.1145/3287324.3287478

[4] R Flatland, I Goldstein, ML Egan, S Vandenberg, M Fryling, and S Small. 2018 Connecting Colleges/Universities and Local High Schools: A New Model for High School CS Teacher Development. In Proceedings of the 49th ACM Technical Symposium on Computer Science Education - SIGCSE '18, 958-963. https://doi.org/10.1145/3159450.3159570

[5] J Goode, J Margolis, and G Chapman. 2014. Curriculum is not enough: the educational theory and research foundation of the exploring computer science professional development model. In Proceedings of the 45th ACM technical Symposium on Computer Science Education - SIGCSE '14, 493-498. https://doi.org/10.1145/2538862.2538948

[6] J Gray, K Haynie, S Packman, M Boehm, C Crawford, and D Muralidhar 2015. A Mid-Project Report on a Statewide Professional Development Mode for CS Principles. In Proceedings of the 46th ACM Technical Symposium on Computer Science Education - SIGCSE '15, 380-385. https://doi.org/10.1145/2676723.2677306

[7] J Kitzinger. 1995. Qualitative research. Introducing focus groups. BMF (Clinical research ed.) 311(7000), 299-302. https://doi.org/10.1136/BMJ.311.7000.299

[8] D Leyzberg and C Moretti. 2017. Teaching CS to CS Teachers: Addressing the Need for Advanced Content in K-12 Professional Development. In Proceedings of the 2017 ACM SIGCSE Technical Symposium on Computer Science Education - SIGCSE '17, 369-374. https://doi.org/10.1145/3017680.3017798

[9] M Menekse. 2015. Computer science teacher professional development in the United States: a review of studies published between 2004 and 2014 $\begin{array}{llll}\text { Computer } & \text { Science } & \text { Education } & \text { 25(4), }\end{array}$ https://doi.org/10.1080/08993408.2015.1111645

[10] R Morelli, C Uche, P Lake, and L Baldwin. 2015. Analyzing Year One of a CS Principles PD Project. In Proceedings of the 46th ACM Technical Symposium on Computer Science Education - SIGCSE '15, 368-373. https://doi.org/10.1145/2676723.2677265

[11] T Neutens and F Wyffels. 2018. Bringing Computer Science Education to Secondary School: A Teacher First Approach. In Proceedings of the 49th ACM Technical Symposium on Computer Science Education - SIGCSE '18, 840-845. https://doi.org/10.1145/3159450.3159568

[12] D Passey. 2017. Computer science (CS) in the compulsory education curriculum: Implications for future research. Education and Information Technologies 22(2), 421-443. https://doi.org/10.1007/s10639-016-9475-z

[13] TW Price, V Cateté, J Albert, T Barnes, and DD Garcia. 2016. Lessons Learned from "BJC" CS Principles Professional Development. In Proceedings of the 47th ACM Technical Symposium on Computing Science Education - SIGCSE '16, 467-472. https://doi.org/10.1145/2839509.2844625

[14] M Roberts, K Prottsman, and J Gray. 2018. Priming the Pump: Reflections on Training K-5 Teachers in Computer Science. In Proceedings of the 49th ACM Technical Symposium on Computer Science Education - SIGCSE '18, 723-728. https://doi.org/10.1145/3159450.3159560

[15] J Ryoo, J Goode, and J Margolis. 2015. It takes a village: supporting inquiryand equity-oriented computer science pedagogy through a professional learning community. Computer Science Education 25(4), 351-370. https://doi.org/10.1080/08993408.2015.1130952

[16] R Santo, S Vogel, LA DeLyser, and J Ahn. 2018. Asking "CS4What?" as a Basis for CS4All: Workshop Tools to Support Sustainable K-12 CS Implementations. In Proceedings of the 49th ACM Technical Symposium on Computer Science Education - SIGCSE '18, 678-686. https://doi.org/10.1145/3159450.3159644

[17] M Webb, N Davis, T Bell, YJ Katz, N Reynolds, DP Chambers, and MM Sysło. 2017. Computer science in K-12 school curricula of the 21st century: Why, what and when? Education and Information Technologies 22(2), 445-468. https://doi.org/10.1007/s10639-016-9493-x
[18] EN Wiebe, L Williams, K Yang, and C Miller. 2003. Computer Science Attitude Survey. North Carolina State University Technical Report TR-2003-1.

[19] A Yadav, S Gretter, S Hambrusch, and P Sands. 2016. Expanding computer science education in schools: understanding teacher experiences and challenges. Computer Science Education 26(4), 235-254. https://doi.org/10.1080/08993408.2016.1257418

[20] KS Yoon, T Duncan, SW-Y Lee, B Scarloss, and KL Shapley. 2007. Reviewing the Evidence on How Teacher Professional Development Affects Student Achievement. Regional Educational Laboratory Southwest (Nf1). Retrieved from https://eric.ed.gov/?id=ED498548

[21] Computer Science For All. Retrieved from https://obamawhitehouse.archives.gov/blog/2016/01/30/computer-science-all

[22] Blockly Games: Maze. Retrieved from https://blocklygames.appspot.com $/$ maze?lang=en 